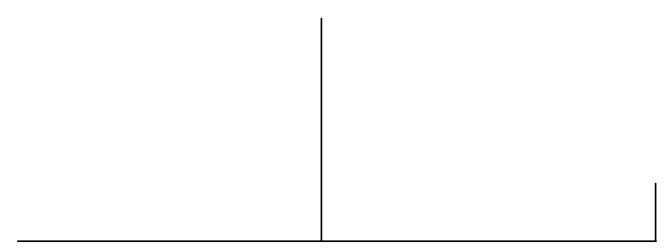

Rev. Latinoam. Psicop. Fund., II, 3, 159-165

\title{
C'est toujours la même chose': Charcot e a descrição do Grande Ataque Histérico
}

\author{
Mario Eduardo Costa Pereira
}

Em uma passagem de sua autobiografia, publicada em 1925, Freud comenta que o que mais o impressionara em seu contato com Charcot, durante os quase cinco meses de seu estágio com ele na Salpêtrière, "foram suas últimas investigações acerca da histeria, algumas delas levadas a efeito sob meus próprios olhos”2. De fato, Freud e todos os inúmeros freqüentadores do "Setor de epilépticos simples", dirigido por Charcot, presenciaram fatos extraordinários naqueles anos de 1885-86.

O personagem era fascinante. À época, o doutor Jean-Martin Charcot já era considerado o maior especialista em doenças nervosas do mundo. Cabeças coroadas de toda Europa e da América, como o próprio imperador D. Pedro II, deslocavam-se a Paris em busca de seus serviços. Sua mansão no Boulevard SaintGermain era um dos endereços mais destacados da elite parisiense. Os salões de sua residência serviam de palco

1. “É sempre a mesma coisa!”, in J.M. Charcot. L’hystérie: textes choisis et présentés par E. Trillat. Toulouse, Privat, 1971, p. 117.

2. S. Freud (1893). “Charcot”, E.S.B., vol. XX. Rio de Janeiro, Imago, 1976, p. 24. 


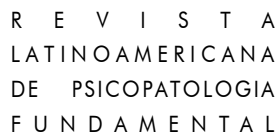

para grandes festas e saraus que reuniam médicos, políticos, artistas e intelectuais de renome.

Na Salpêtrière, Charcot reinava como mestre absoluto. Seu seminário semanal, as famosas Leçons du Mardi, era assistido não apenas por médicos e pesquisadores provindos de toda a Europa, como também por homens importantes da sociedade e da cultura. O famoso quadro pintado por Brouillet, intitulado "Uma aula clínica do Dr. Charcot”, mostra o professor examinando uma paciente sob os olhos atentos de uma platéia formada por alguns daqueles que viriam a ser os maiores nomes da psicologia, da psiquiatria e da neurologia francesas na virada do século: Babinski, Ribot, Brissaud, Pierre-Marie, Gilles de la Tourette, Ferré...

Charcot havia ingressado na Salpêtrière em 1862, trabalhando com seu colega Alfred Vulpian em pesquisas sobre as patologias nervosas. Dez anos depois, ele próprio ocuparia a cátedra de anatomia patológica. Essa formação de patologista seria fundamental para o desenvolvimento do método anátomo-clínico com o qual abordaria com tanto sucesso o campo ainda desconhecido da neurologia.

Titular desde 1882 da primeira cátedra de Clínica de Doenças Nervosas de que se tem notícia (criada pelo ministro Gambetta especificamente em sua intenção), Charcot desenvolve uma vigorosa obra clínica e semiológica que viria a constituir um dos pilares da neurologia moderna. Seus trabalhos sobre a esclerose lateral amiotrófica, sobre a esclerose em placas, sobre as artropatias tabéticas e sobre as localizações medulares constituem colaborações decisivas, que ainda hoje mantêm todo seu valor. ${ }^{3}$

Valendo-se de um rigoroso método de observação e de comparação de casos, Charcot tentava demonstrar que a histeria pertencia de direito e de fato ao rol das doenças neurológicas. Para isso, era-lhe necessário mostrar que por trás da infinita variedade de suas formas de apresentação clínica - sob as quais ela costumava confundir os médicos e desqualificar-se como entidade digna de crédito científico - a histeria teria uma regularidade sintomatológica mínima, credenciando-se como espécie válida no grande jardim das categorias médicas.

As pesquisas de Charcot com a histeria se iniciaram por volta de 1870, quando o principal de sua obra neurológica já havia sido produzido. O começo de seu trabalho nesse campo psicopatológico deu-se de forma um tanto fortuita. Na época, o péssimo estado de conservação de um dos pavilhões do hospital, o qual abrigava simultaneamente alienados, histéricos e epilépticos ${ }^{4}$, obrigou a redistribuição dos pacientes ali instalados. Essa intercorrência administrativa forneceu a ocasião para

3. Cf. J. Postel \& C. Quetel (orgs.). Nouvelle histoire de la psychiatrie. Toulouse, Privat, 1983, pp. 603-605

4. Cf. E. Trillat, in J.M. Charcot. L'hystérie: textes choisis et présentés par E. Trillat, op. cit., p. 8. 


\section{CLÁSSICOS DA}

PSICOPATOLOGIA

que se procedesse a um reagrupamento mais sistemático desses indivíduos, segundo as características de suas patologias, o que permitiria um acompanhamento clínico mais adequado e uma observação científica mais rigorosa.

Coube naturalmente a Charcot, o médico mais renomado da instituição, a tarefa de criar um serviço especial para histéricos e epilépticos simples. Esses dois grupos patológicos constituíam as duas "Grandes Neuroses", segundo a terminologia charcotiana, que designava aqueles pacientes apresentando quadros convulsivos para os quais não se encontrava evidência de lesão cerebral à autópsia. Os conhecimentos a respeito de ambas as categorias ainda eram extremamente precários. Sobre a histeria, em particular, pairava a suspeita de que se tratasse apenas de um quadro de simulação ou de exagero das emoções.

Essa era notadamente uma das leituras a que dava margem a concepção de Paul Briquet. Em seu famoso tratado sobre a histeria, este eminente predecessor de Charcot acompanhava o ponto de vista de Sydenham, segundo o qual os sintomas histéricos simulariam as paixões tendo, portanto, valor de expressão. Tal formulação sobre a histeria colocava-a numa posição muito desconfortável para que pudesse ser aceita na comunidade médica como uma doença propriamente dita.

A aposta de Charcot foi a de aplicar à histeria o mesmo método anátomoclínico que já havia dado resultados tão produtivos no estudo de outras doenças neurológicas. Na verdade, ele pensava, como Briquet, que a histeria era essencialmente uma doença cerebral, ao mesmo título que tantas outras que já estudara.

O método anátomo-clínico ${ }^{5}$ exigia uma profunda fineza clínica no exame do paciente. Isso porque os estudos de patologia cerebral já reconheciam uma série de lesões e de alterações morfológicas típicas daquele órgão, reveladas pelas peças de autópsia. Contudo, não se sabia ao certo ao que tais lesões correspondiam no campo da clínica. O método anátomo-clínico visava, portanto, estabelecer de forma segura essas relações entre semiologia e morfologia. Era esse o procedimento que orientaria o trabalho de Charcot com suas pacientes histéricas. Tratava-se, em primeiro lugar, de descrever nos mínimos detalhes todas as nuances de apresentação sintomatológica da "doença" para, em seguida, estabelecer as relações com as lesões propriamente ditas. Na falta de evidência de tal alteração anatômica, a lesão deveria ser suposta como apenas "funcional”, ou seja, corresponderia a uma desregulação de natureza biológica de certas funções cerebrais.

Charcot procedia de maneira sistemática o exame de seus pacientes. Abolindo a tradição da "visita ao leito do doente", Charcot preferia chamá-los a seu consultório, onde eram trazidos um a um por seus assistentes e colocados, despidos, diante do

5. Cf. E. Trillat. História da histeria. São Paulo, Escuta, 1991. 


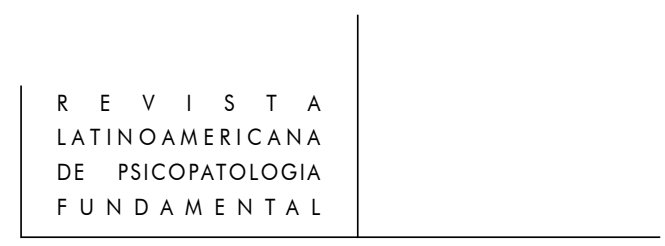

olhar escrutinador do patron. Conta-se que ele permanecia por longo tempo em silêncio, observando minuciosamente as mínimas atitudes e manifestações do corpo do examinado. Em seguida, dava ordens para que conduzissem o paciente de volta à enfermaria e que chamassem o seguinte.

Sua atenção voltava-se sobretudo para as diferenças entre as manifestações clínicas, de modo que ele tornava-se progressivamente mais capacitado a identificar as regularidades e suas variações. Seu objetivo era descrever as formas típicas nas quais a doença expressava sua sintomatologia de forma completa e inequívoca.

Com esse método, Charcot foi capaz de demonstrar que embora tanto a histeria quanto a epilepsia essencial pudessem se apresentar sob a forma de convulsões, uma e outra constituíam entidades clínicas completamente distintas. Assim, aos fenômenos histéricos do tipo convulsivo, Charcot deu a denominação de hísteroepilepsia, para distingui-la da epilepsia propriamente dita.

Além disso, seu trabalho deu respeitabilidade à tese de que a histeria não aparecia unicamente nas mulheres, podendo também ser observada nos homens. Quando Freud tentou sustentar esse mesmo ponto de vista junto a seus colegas da Sociedade de Medicina de Viena, logo após seu retorno de Paris, acabou por enfrentar uma enorme oposição, tal era a convicção no meio germânico de que a histeria era uma doença ligada ao feminino. O próprio Meynert desafiou Freud publicamente a apresentar o relato de alguns casos de histeria masculina, o que resultou na publicação do artigo "Observação sobre um caso grave de hemianestesia em um homem histérico”, em dezembro de 1886 na Wiener med. Wochenschrift.

Charcot demonstrou, também, que a histeria não se resume a uma simples simulação, tratando-se de uma manifestação patológica sobre a qual o sujeito não tem controle voluntário. No final de sua obra, interessou-se, ainda, pela histeria traumática, propondo que o traumatismo induziria estados hipnóides em sujeitos predispostos à histeria. ${ }^{6}$ Durante esses estados, análogos àqueles produzidos pelo hipnotismo, o sujeito ficaria à mercê de auto-sugestões que passariam a funcionar de modo autônomo e parasitário no psiquismo do indivíduo. ${ }^{7}$ Quando da elaboração teórica dos "Estudos sobre a histeria", Freud e Breuer retomariam a teoria charcotiana dos chamados "estados hipnóides" na histeria traumática.

Charcot sustentou até o final de sua obra que a histeria seria resultante de uma perturbação funcional do sistema nervoso, cuja expressão sintomatológica só

6. Segundo Charcot, apenas os histéricos seriam hipnotizáveis. Histeria e hipnotismo repousariam sobre a mesma matriz patológica. O hipnotismo fornecia a Charcot a possibilidade de demonstrar o aparecimento dos sintomas histéricos, em particular as paralisias, a partir da instalação de um estado psíquico particular. Com o hipnotismo, a abordagem charcotiana da histeria deixa de ser apenas de observação naturalista para ser, também, experimental.

7. Cf. E. Trillat. História da histeria, op. cit., pp. 156-161. 


\section{CLÁSSICOS DA}

PSICOPATOLOGIA

se dá de forma completa na Grande Histeria. Segundo ele, a Grande Histeria seria constituída por sintomas permanentes (ou "estigmas") e pela crise convulsiva histérica ou hístero-epilepsia. As demais apresentações clínicas da histeria não seriam senão formes frustres dessa entidade fundamental.

O primeiro grupo de sintomas, os que permanecem presentes o tempo todo, traduzir-se-ia essencialmente pela presença de regiões anestésicas e dos chamados pontos histerogênicos, ou seja, certas zonas específicas do corpo, variáveis de indivíduo para indivíduo, cuja estimulação moderada levaria ao desencadeamento do ataque histérico e cuja estimulação intensa durante o ataque forçaria a sua interrupção. Há vários relatos em suas Leçons du Mardi dando conta de que Charcot realizava a estimulação dos pontos histerogênicos durante as apresentações de pacientes no intuito de desencadear o grande ataque histérico diante de seu público, buscando com isso demonstrar a realidade e a regularidade da hístero-epilepsia.

$\mathrm{O}$ ataque histérico ou a hístero-epilepsia, por sua vez, constituiria o elemento central da histeria. Charcot descreve quatro fases desse ataque que desenrolar-seiam segundo uma seqüência típica. ${ }^{8}$ Após um curto período prodrômico de "aura histérica", com "distanciamento" do contato com o mundo imediato, agitação, confusão e mesmo de dores (sobretudo ovarianas) iniciaria a primeira fase do ataque: a fase epileptóide, a qual manifesta-se por aumento do tônus muscular (contração localizada ou generalizada da musculatura) intercalado por agitação clônica dos membros e do tronco. É o período que mais se assemelha a uma crise epiléptica. Nessa fase ocorreria, por vezes, o chamado "arco histérico": a paciente coloca-se num estado de tal contratura muscular que seu corpo curva-se, apoiado apenas na cabeça e nos calcanhares.

Em seguida, instala-se o período de clownismo, manifestado por posturas e atitudes bizarras. Sua conduta é francamente infantil e inconseqüente. O corpo assume posturas estranhas e de caráter por vezes grotesco.

A terceira etapa é a das atitudes passionais, durante a qual a paciente mostraria expressões de beatitude, de enamoramento, de terror ou de outras formas de experiência afetiva intensa. A teatralidade do ataque encontra aqui seu ponto culminante. Finalmente, a resolução ocorreria em um período de delírio, durante o qual a paciente parece confusa ou em estado de fuga e passa a falar de forma incompreensível, irracional, dizer obscenidades ou, ainda, a revelar segredos e pensamentos íntimos.

Quando todas essas etapas manifestam-se integralmente e nessa seqüência "canônica” teríamos o grande ataque histérico. As formes frustes ou petite hystérie

8. Cf. G. Didi-Huberman. Invention de l'hystérie - Charcot et l'iconographie photographique de la Salpétrière. Paris, Macula, 1982. 


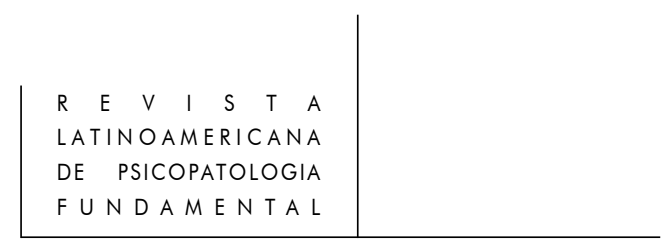

seriam aquelas onde uma ou mais fases são omitidas, aparecem fora de ordem ou são muito brandas.

O que interessa a Charcot com a descrição do grande ataque histérico é demonstrar a regularidade do fenômeno, a delimitação clara do quadro clínico. Ele freqüentemente interpelava seus alunos dizendo que bastava observar de forma séria e sem preconceitos, que o quadro clínico apareceria de forma evidente aos olhos de todos, que não poderiam senão constatar: c'est toujours la même chose!

O grande ataque histérico seria um elemento patológico irredutível, expressão direta da doença cerebral funcional subjacente. Mesmo que nem sempre ele se manifestasse com todas as suas etapas, era a regularidade do processo mórbido que nele se revelava. O grande ataque deveria ter manifestações "válidas para todos os tempos, para todos os países, em todas as raças”. Daí seu esforço de constituir toda uma iconografia que deixasse registrada a evidência da regularidade da grande histeria, fosse através do registro fotográfico das diferentes etapas do ataque, fosse através de desenhos retratando as expressões das pacientes, fosse ainda através de obras de grandes pintores que, em suas percepções magistrais, teriam registrado para a posteridade as fases típicas do ataque.

Com isso, Charcot procurava também responder a uma crítica proveniente de várias partes do mundo, sobretudo da Escola de Nancy, liderada por Liébault e Bernheim, segundo a qual a Grande Histeria existiria apenas na Salpêtrière, pois no fundo dependeria de um fenômeno de sugestão coletiva.

Para Charcot, como vimos, a histeria deveria ser considerada como uma doença de tipo neurológico. Não podendo demonstrar nenhum tipo de lesão ao exame anátomo-patológico (como de resto é também o caso para a epilepsia essencial), ele propõe tratar-se de uma "lesão dinâmica", de causa exclusivamente hereditária. Ou seja, a histeria seria uma perturbação funcional do sistema nervoso. A carga hereditária funcionaria como disposição do indivíduo a esta patologia, a qual seria efetivamente desencadeada quando houvesse exposição a um agent provocateur, que poderia ser de natureza física, emocional ou traumática. A forma clínica "Grande Ataque Histérico” constituiria, nesse contexto, a expressão completa da condição mórbida subjacente.

Tal ponto de vista estritamente biológico-hereditário seria criticado por Freud em seu obituário de Charcot, afirmando que este "não deixou espaço algum para a aquisição da doença nervosa”"10.

Como se sabe, Freud ofereceu-se para traduzir os trabalhos de Charcot para o alemão, pedido que foi prontamente acolhido pelo neurologista. Entre outros

9. Cf. J. Postel \& C. Quetel (orgs.). Nouvelle histoire de la psychiatrie, op. cit.

10. S. Freud (1893). “Charcot”, op. cit., p. 34. 


\section{CLÁSSICOS DA}

PSICOPATOLOGIA

escritos, Freud traduziria as Leçons du Mardi dos anos 1887-88, ou seja, ele ocupouse do texto que a Revista Latinoamericana de Psicopatologia Fundamental traduziu para este número.

Esteta, que se autodefinia como um visuel, mestre do método clínico, homem da instituição médica, Charcot procurava, como um pintor, apreender e fixar a imagem do quadro clínico da histeria. Embriagado pela volúpia de sua posição de mestre e de epígono da ciência, permaneceu cego aos efeitos de seu próprio desejo e de seu lugar naquela cena da Salpêtrière, palco de representações de dramas e paixões impossibilitadas de se darem a reconhecer de outra maneira.

Não deixa, portanto, de ser algo fascinante que essa mesma personalidade, vítima de um enorme equívoco que ela própria engendrou sem se dar conta, tenha marcado Freud tão profundamente e tenha inscrito em sua memória e em seu processo de construção da psicanálise uma lição jamais esquecida: “La théorie, c'est bon. Mais cela n'empêche pas d'exister”11. 